\section{No. 4655 January 17,1959}

is incompatible with long-range order, the corresponding arrangement of molecules must be a fluid."

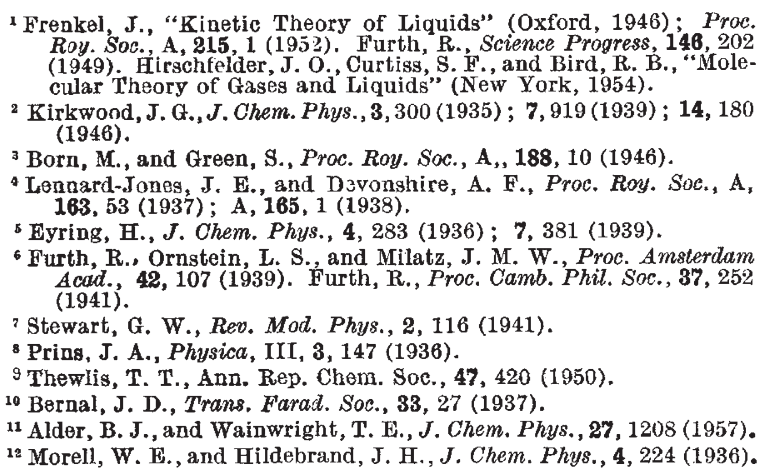

${ }^{3}$ Born, M., and Green, S., Proc. Roy. Soc., A,, 188, 10 (1946).

- Lennard-Jones, J. E., and Davonshire, A. F., Proc. Roy. Soe., A, $163,53(1937) ; \mathrm{A}, 165,1(1938)$.

s Eyring, H., J. Chem. Phys., 4, 283 (1936); 7, 381 (1939).

' Furth, R., Ornstein, L. S., and Milatz, J. M. W., Proc. Amsterdam Acad., 42, 107 (1939). Furth, R., Proc. Camb. Phil. Soc., 37, 252 (1941)

'Stewart, G. W., Rev. Mod. Phys., 2, 116 (1941).

s Prins, J. A., Physica, III, 3, 147 (1936).

9 Thewlis, T. T., Ann. Rep. Chem. Soc., 47, $420(1950)$.

${ }^{10}$ Bernal, J. D., Trans. Farad. Soc., 33, 27 (1937).

${ }^{11}$ Alder, B. J., and Wainwright, T. E., J. Chem. Phys., 27, 1208 (1957).

${ }^{12}$ Morell, W. E., and Hildebrand, J. H., J. Chem. Phys., 4, 224 (1936).

13 Cayley, 98).

A., "Collected Mathematical Papers", 5 (Cambridge, 1889 (Pt. 1), T. P., Phil.

1 (Pt, 1), "183 (1857). Toth, L. F., "Lagerungen in

${ }^{16}$ Marvin, J. W., Amer. J. Bot., 26, 280 (1939). (See also Lewis, F. T., ibid., 30, 74 (1943).)

17 Frank, F. C., and Kaspar, J. S., Acta Cryst., 11, 184 (1958).

${ }_{18}$ Reynolds, Osborne, Proc. Roy. Inst., Scientific Papers, 7, 217 (1835).

19 Simon, F., Trans. Farad. Soc., 33, 65 (1937).

${ }^{20}$ de Boer, J., Proc. Ruy. Soc., A, 215, 4 (1952). de Boer, J., and Michels, A., Physica, 5, 95 (1938).

${ }^{21}$ Kikuchi, R., Phys. Rev., 81, 988 (1951); J. Chem. Phys., 19, 1230 (1951).

22 Jones, G. O., and Walker, P. A., Proc. Phys. Soc., B, 89, 1348 (1958).

${ }^{23}$ Debye, P., N.R.C. Conference on Non-crystalline Solids (1958).

${ }^{4}$ Danford, M. D., Agsar, P. A., Bredy, M. A., and Levy, H. A., Acta Cryst., 10, 829 (1957)

25 Bernal, J. D., Proc. Roy. Soc., A, 163, 320 (1937).

${ }^{26}$ Smith, C. S., Amer. Soc. Met., 65 (1952); Acta Metallurg., 1, 295 (1953).

${ }^{27}$ Meijering, L. J., Philips Res. Rep., 8, 270 (1953); Acta Metallurg., 1, 607 (1953).

\title{
INTERNATIONAL CONFERENCE ON SCIENTIFIC INFORMATION
}

$\mathrm{T}$

HE National Academy of Sciences-National Research Council in Washington was co-sponsor with the U.S.A. National Science Foundation and the American Documentation Institute in arranging an International Conference on Scientific Information during November 16-21 in the Mayflower Hotel, Washington. The Conference opened with an address from Sir Lindor Brown, biological secretary of the Royal Society, and this was followed by a series of sessions, each of three hours, devoted to a section of the Conference subjects. The purpose of the Conference was to bring together scientists and information specialists for discussions of current research and problems concerning primarily the storage and retrieval of information. This is a narrow seope compared with the Royal Society Conference on Scientific Information Services held in 1948. Nevertheless, preprints of seventy-five papers occupying 1,420 pages were circulated to all participants some weeks before the Conference. These participants numbered about one thousand, and for the purpose of facilitating discussion the authors and members of seven discussion panels, each of 9-13 persons appointed well in advance of the meeting, were grouped in a forward section of the Conference hall and permitted to comment throughout the meeting. The remainder of the participants were silent observers during the sessions, but there was ample opportunity for discussion outside the Conference hall and in the neighbouring hall, which housed an exhibition of modern storage and retrieval systems devised by commercial organizations. A small historical exhibit illustrating the Royal Society's long and continuing interest in scientific information services was also on view. Arrangements were made for organized visits to institutions in Washington concerned with the retrieval of information. These included the Library of Congress, the U.S. Patent Office, the National Bureau of Standards Data Processing Systems Division, National Library of Medicine, the Department of Agriculture Library and the Institute of Languages and Linguistics of Georgetown University, where a machine translation of Russian texts in organic chemistry using an I.B.M. 704 computer was demonstrated.
Sir Lindor Brown in the opening address directed attention to the desirability of discipline and restraint on the part of the authors of scientific papers. $\mathrm{He}$ said there is much scientific literature which need never be produced, and of that which justifies its appearance 80 per cent could be improved by drastic reduction in length and by clear writing. He urged scientists to publish the results of their work once and once only, and not in a multiplieity of guises. $\mathrm{He}$ went on to say: "However we improve the raw material of information there will still remain poor papers, unnecessary papers, trivial papers and repetitious papers. What are we to do with them ? What is to be stored? Is it the fruit of the tree of knowledge or is it the fallen leaves? For my part I should be happy if the fruit only were preserved, as I cannot conceive of any collecting and storage system adequate to cope with the world's output of scientific information as it grows at present, and I view with only a little compunction the prospect of the loss of minor contributions to knowledge provided that the ripe fruit can be preserved. The few fallen leaves of my own work are already losing their individuality as they dissolve into the rich compost of the background knowledge of the rising generation. Their individuality is lost, but they have contributed a little to the vigour of the pushing young shoots at the top of the tree-and of course I have a fruit or two up my sleeve still. Of course we have the difficulty: Who is to decide what is the fruit and what is the fallen leaf? Can any information service work on an eclectic principle? I think it can. But only with the full co-operation of the user and the maker of information".

As mentioned above, the primary purpose of the Conference was discussion. No attempt was to be made to arrive at conclusions in the form of recommendations. The Conforence certainly achieved its objects of exposing the problems of retrieval of information and of bringing the interested parties together. Although each panel was at liberty to deal with its subject in its own way, the general procedure adopted was to assume that the papers had been read; the panel members then commented on the subject, referring to papers as desired, and a period of general discussion followed. 
Panel 1 concerned literature and reference needs of scientists. The papers chiefly related to surveys of information requirements of scientists in a variety of different research organizations, and methods by which research workers find information. A fact brought out by the papers was that communication of scientific information is done as much through personal conversation as by reading the literature. It was stated that the volume of scientific literature is doubling every seven years. It was evident that it is impossible to make generalizations in methods of communicating information and that not only do methods vary from subject to subject but also from user to user and according to the uses to which the information is to be put. Studies on the habits of scientists in acquiring information are still imperfect, but may be the bases for action in certain local situations. The present services go a considerable way towards meeting the needs of the competent research worker in his own field, although the use of abstracts seems to be on the decline and the research worker is not so well served when he wishes to explore a field other than that with which he has some familiarity. The importance of the unplanned contact with new scientific information was stressed.

A plea was made for more studies of the physiological nature of recognition and memory. One contributor urged that neurones as well as electronics have a role in the retrieval of information. Readingrates of students of about equal standard were reported to vary from $2 \cdot 5$ to $9 \cdot 8$ words a second, and further studies on this and the related problem of reading and visual fatigue were suggested as a fruitful field of investigation.

The second Panel discussed the effectiveness of abstracting and indexing services. The discussion reploughed familiar ground in relation to authors' abstracts versus non-author abstracts, informative abstracts versus indicative abstracts, the role of highly centralized general abstracts (as in Moscow) and specialist abstracts (as in the Commonwealth Agricultural Bureaux), and little that was new emerged. One study, however, reported that in spite of all that is said about biasing abstracts for particular classes of readers, there is a growing tendency by many abstracting agencies to use authors' abstracts. There seemed to be a generally favourable opinion that if authors' abstracts are properly edited they can be of considerable service, and the action taken by the Abstracting Board of the International Council of Seientific Unions in encouraging this in physics abstracting was supported. On the other hand, the delays in issuing some abstracts is becoming so great that in rapidly developing subjects they are of little use for current awareness, and alternative means, for example the quick circulation of the titles of papers as in Current Chemical Papers, will have to be investigated. The importance of indexing was stressed by Dr. E. J. Crane, of Chemical Abstracts, and in commenting on the possible use of mechanical aids in abstracting he warned against the danger of departing from existing high standards in abstracting and indexing.

The third Panel was concerned with the effectiveness of monographs, compendia, and specialized centres. Some time was devoted to discussing reviews, and it was generally agreed that an insufficient number of first-rate people are willing to give time to their compilation for the benefit of a variety of users - the specialist, the specialist in related fields, the teacher and general reader. The suggestion was made that review writing should be a joint effort of a junior who did the searching of the literature and an experienced scientist who would provide the necessary eritical judgment. The review should preferably deal with concepts and leave data to special compendia. The writing of monographs seems to be going out of fashion, although it remains important in biology. An experiment in the U.S.S.R. was described where the Institute of Scientific Information plans to issue a series of monographs attempting to cover the whole field of science : the Russian definition of a monograph is a scientific work which concentrates and develops all aspects and facets of a given scientific discipline and requires strict objectivity from the author. The chief difficulty will be the shortage of suitable authors.

Dr. E. Pietsch, director of the Gmelin-Institut, Germany, described in detail the organization of the "Handbuch für der Anorganische Chemie", where the evaluation of the data is by far the most costly operation in preparing the text. The eighth edition will consist of 60,000 pages and will cover two hundred years of the subject up to 1950 . If the "International Critical Tables" were to be re-issued on the same lines as twenty-five years ago, it might require several hundred volumes. The issue of abbreviated tables of data in the form of handbooks for specific uses was strongly urged, and a suggestion was made for increased use of directories of scientific workers and their interests to assist the communication of information. There was also some discussion on the increased use of technical reports, only a fraction of which, however, is abstracted in the abstracting journals because the editors of the latter consider the technical report to lack the careful preparation imposed on the writing of a paper for a journal and because a report, or part of it, is liable to be published again as a paper. The need to give greater emphasis to the value of books in information services was stressed.

A variety of national scientific information centres were described ; for example, those in the U.S.S.R., India, France, Japan, Czechoslovakia and Poland. A novel feature of a Czechoslovak service is that all inquiries must be made by telephone, as it is thought that only by this means can the inquiry be sufficiently well defined by discussion to make the information service really efficient. The Soviet representative advocated the centralized information centre and quoted Vavilov as saying that "the contemporary man of research is in the same position in relation to the holdings of libraries of the world as the gold prospector faced by the jungle". The centralized institute dealing with national and international scientific literature was adopted in the U.S.S.R. because all knowledge is organically interconnected, and in one institute, where are concentrated specialized personnel, all collective data, etc., knowledge from one field, for example, physics, can be readily related to other fields such as chemistry, biology, metallurgy. In Poland, where there is an information service in applied science, only the central direction is concentrated in Warsaw and a decentralized system, using eighty different regional institutions and a hundred or more industrial centres, is found to be effective in providing an organized person-toperson contact.

Panel 4 considered the organization of information for storage and search, and devoted some time to the comparison of the characteristics of existing systems. It was considered that, at present, each specific 
problem requires a system tailored to the special demands on it and the need for further experiment was admitted. Where machines have been used, it seems too early to generalize on their merits or demerits, and consideration of the replacement of the human brain by a machine in a system of retrieval only emphasized the need for any machine to have a good master.

Panel 5 discussed the organization of information for storage and retrospective search. There were twenty preprinted articles in this section, many dealing with the classification or coding of informa. tion in specialized fields, in such a way as to enable mechanical retrieval. Words were regarded as being too imprecise for large-scale mechanical information retrieval, and it was suggested that a rigorous mathematical theory of systems should be sought for future development. Further study was proposed of language and the nature of communication-a multi-stage process with the interplay of ideas in a highly unorganized state. In the meantime, the solution of narrow practical problems seemed the more profitable line of advance. Even with a highspeed machine of long memory, the intellectual problem of searching the literature will remain. Machines require careful programming, and it was stated that all they can achieve is to do clerical work more quickly.

Panel 6 concerned itself with the possibility of a general theory on the organization of information for storage and retrospective search. This gave rise to a great deal of discussion, and for those who are expert in one or more systems this may well turn out to have been a profitable occasion, for it appeared that no existing theory can be directly applied, and much more experiment, discussion and thought will be necessary before a general theory can be evolved. The greatest difficulty is to provide for the interaction between the inquirer and his information sources ; thus, any general theory must accommodate the learning process and the consequent need to modify itself continuously. It seems likely that, with so much interest in the subject, something constructive may emerge within the next few years.

Panel 7 covered a wide range as it discussed the responsibilities of governments, scientific societies, universities and industry for improved information services and research. The Panel took an early opportunity of pointing out that the only indis. pensable person in the whole subject is the scientist, and that through his societies he is the principal maker and user of scientific information. Scientific societies should, if possible, be self-supporting in the publication of original work, but any help required in the secondary information services should have government support, as scientific information is a national resource. As a user, the specialist usually organized his own search, and it was suggested that universities might encourage, more than is done at present, young research workers in learning how to use the literature of their subject as well as how to produce it by the better writing of their papers. Scientific societies might encourage authors not only to submit abstracts but also provide key index words to facilitate the editing of abstracts and indexing.

Nowadays some national governments are largescale users and producers of information and have responsibilities for its proper distribution. This varies from the small country with a relatively recent acquaintance with scientific research, where information services receive their main support from international agencies, for example, from Unesco through a regional office, to large scientifically advanced countries where national funds are provided on a large scale and where government agencies provide a plan for stimulating and supporting scientists and engineers in dealing with information problems. Whatever method is employed, the wholehearted co-operation of those who produce the information is necessary.

In the international field the work of the Abstracting Board of the International Council of Scientific Unions was cited as a good example of co-ordination of existing services. The Panel was not in favour of trying to establish an international scientifie information centre at present, but rather favoured the co-ordination of national services, for example, through national library services. The trend should be towards more national centres and more international co-ordination. A statistical survey of the economics of the various types of national centres would be helpful in this connexion.

There were no formal conclusions of the Conference, but hopes were expressed that some more formal international organization might follow, possibly through national academies of sciences. Whether this happens or not, the participants in this International Conference on Scientific Information were stimulated by attending it, and it will not be surprising if they in turn stimulate further action towards a renewed consideration of the many and growing problems of scientific information services in their respective countries. That those concerned in the United States are active is obvious.

D. C. M MRTIN

\section{OBITUARIES}

\section{Sir Hubert Wilkins}

THE death occurred in New York early in December of Sir Hubert Wilkins; he was seventy years old. He will be remembered as a pioneer both in arctic and in antarctic travel.

Wilkins first visited the Arctic as second-in-command of Vilhjalmur Stefansson's Canadian Arctic Expedition which went north in 1913. Wilkins remained a member until 1917 and during these years he became expert in travel on arctic pack-ice. He himself, however, was always keener on air travel and was probably the first man to fly in the Antarctic. His flights in the Arctic, after more than one attempt, culminated in 1928 in an adventurous journey from the north of Alaska to Spitsbergen, for which he received the Founder's Medal of the Royal Geographical Society. His arrival in the latter region stirred the people of Great Britain as no other arctic flight had done. $\mathrm{He}$ wrote an exciting dispatch describing the journey for The Times; it was one of the best travel reports ever written.

An important feature of Wilkins's explorations was his work as a naturalist. He made collections in Australia ; and he joined Shackleton on the Quest, for example, as a collector of natural history specimens. Wilkins was also in the Antarctic with 